\title{
Creative Personality Profile in Social Sciences: The Leading Role of Autonomy
}

\section{Christiane Kirsch}

University of Luxembourg, Luxembourg

E-mail address: christijeanne.kirsch@gmail.com
Todd Lubart

Université Paris Descartes, France

E-mail address: todd.lubart@parisdescartes.fr

\section{Claude Houssemand}

University of Luxembourg, Luxembourg

E-mail address: claude.houssemand@uni.lu

ARTICLE INFO

Keywords:

Creativity

Social sciences

Perseverance

Risk taking

Autonomy

Psychoticism

Ego-strength

\section{Article history:}

Received 18 December 2014

Received in revised form 29 May 2015

Accepted 12 August 2015

ISSN: 2354-0036

DOI: 10.1515/ctra-2015-0020
A B STRACT

The literature on creativity has often focused on the analysis of artists and scientists. The ability to generalize these findings to respective professional sub-disciplines is examined. In particular, the present study addresses the generalizability of the personality profile of creative scientists to creative social scientists. Autonomy was found to be the most important personality feature for creativity in social sciences. These results suggest the importance of fostering an autonomous working style.

\section{Differential Influence of Personality on Creativity}

Three major domains of creative expression are often distinguished: artistic creativity, scientific creativity and everyday creativity (Batey \& Furnham, 2006). There is an ongoing debate about the domain generality or domain specificity of creativity. Despite the fact that artistic and scientific creativity share common ground, domain specificity cannot be totally ignored (Baer, 1998). The differential approach reconciles, to some extent, both visions; accordingly, some cognitive and personality characteristics (e.g. analogical or metaphorical thinking, openness) are supposed to be more domain-general (Batey \& Furnham, 2006; Lubart, Mouchiroud, Tordjman \& Zenasni, 2003), whereas others (e.g. knowledge, risk taking) vary in terms of the respective domain (Lubart \& Sternberg, 
1995). In addition, depending on the field of intervention or subdomain within a field, particular cognitive or personality features are more or less involved (Batey \& Furnham, 2006). The present research focuses on the exploration of the degree of generalizability of the creative personality profile, in general, to creative social scientists. According to Feist and Gorman (1998), the definition of a scientist includes the professionals of social sciences. Psychology and education can be perceived as sub-disciplines of social sciences, which are growing fields of study. Currently, there are already thousands of academic journals covering the topic of social sciences.

Personality belongs to the conative component of creativity, which also includes cognitive styles and motivation (Lubart et al., 2003). Generally speaking, there are six personality features that repeatedly have been hypothesized to be related to creativity across domains: perseverance, tolerance of ambiguity, risk taking, individualism, openness and psychoticism (Sternberg \& Lubart, 1995).The present investigation focuses on four of these personality features and on their presumed relation to creativity, particularly the personality features of perseverance, risk taking, individualism and psychoticism. Openness and ambiguity tolerance have been the subject of several previous studies and are not examined in this paper. In addition, according to some authors (e.g. Batey \& Furnham, 2006), openness and ambiguity tolerance (McCrae, 1987) are supposed to be rather domain general. Thus, in the present research a focus is placed on personality features that may show domain specificity in terms of their involvement in creativity.

Whereas psychoticism is supposed to be less pronounced in scientific populations compared to artistic ones (Feist, 1998), comparatively little is known about the degree of domain specificity of perseverance, risk taking and individualism. The present research addresses this gap by examining the relative importance of these personality features in the domain of social sciences. From the between-group perspective, scientists distinguished themselves from non-scientists through (1) higher conscientiousness, (2) higher dominance, achievement orientation and drive, (3) higher independence, introversion, and lower sociability, and (4) higher emotional stability and impulse control (Feist \& Gorman, 1998). From the within-group perspective, creative scientists distinguished themselves from less creative ones through comparatively: (1) higher dominance, arrogance, self-confidence, and hostility, (2) higher autonomy, independence, and introversion, (3) higher drive, ambition, and achievement orientation, and (4) higher openness and flexibility in thought or behaviour (Feist, 1999; Feist \& Gorman, 1998). Dominance, arrogance, self-confidence and hostility are all personality traits associated with psychoticism (Eysenck, 1985). Even if psychopathological tendencies are supposed to be less 
pronounced in scientific populations than in artistic ones (Feist, 1998), they still play an important role (Batey \& Furnham, 2006). Independence, introversion and low sociability are "self-referenced" personality features associated with autonomy (Oztunc, 2011), which will be outlined below. Emotional stability and impulse control are associated with ego-strength (Eysenck, 1995). Finally, drive, ambition and achievement orientation are relevant to high perseverance (Fidelman, 2008; Gruber, 1983; Roe, 1953).

Also, when examining issues of domain specificity, it is important to note that some professional occupations cannot be exclusively attributed to only one creative domain (e.g. arts vs. sciences); there is also some variety within a domain (e.g. a poet and a novelist are both in the literary domain but do rather different kinds of work) (Batey \& Furnham, 2006).

\section{Aims of the study}

The personality profiles of specific professional subgroups from the social sciences are investigated to examine the specificity or generality of the creative personality within this domain. In particular, four personality traits and their presumed relations to creativity will be examined.

\section{Perseverance and creativity}

Perseverance is considered as a core feature of the creative process, especially during the finalization of a creative product (Rossman, 1931). Perseverance intervenes specifically in maintaining a focus on a creative activity despite temporary drawbacks. Perseverance is relevant also during required defence against criticism (Eysenck, 1993), and the necessity to go against the flow and against established ideas (Lubart \& Sternberg, 1995). A lack of perseverance at those specific moments of the creative process results in a withdrawal of cognitive efforts (Lubart \& Sternberg, 1995). Hence, perseverance is involved in transforming creative potential into a creative product. It is particularly relevant for divergent thinking, which requires the repeated proposition of new solution options (Besançon, 2011).

Perseverance can also be perceived in terms of drive or energy. It is best described as the will to work hard and to endure frustration and failures (Fidelman, 2008) or the willingness to expand effort (Cropley, 1997). Creative people are prolific, in part because they are devoted to their work (Roe, 1953). They show passionate and prolonged engagement in a subject (Gruber, 1983). Creative insights seem sudden as they inadvertently pop up into the conscious mind; however, the mind may have long been dealing with the problem before the solution suddenly becomes conscious (Gruber, 1983).

Csikszentmihalyi (1988) compared two groups of gifted adolescents. The first one was faithful to its initial domain of interest after several years of engagement whereas the sec- 
ond one was not. In comparison to the second group, the first group showed higher performance motivation and endurance. Csikszentmihalyi concluded that a passionate and focused character underlies creative dynamism. Creative passion predominates even over personal relationships and civic obligations (Gardner, 1993). From a biographical analysis of 301 creative geniuses, Cox (1926) concluded that "persistence of motive and effort", "confidence in their abilities" and "great strength or force of character" accounted for a significant amount of variance in lifetime achievement, beyond IQ. Howe (1989) examined biographical details of world famous geniuses like Darwin or Einstein. He considered that personality, in particular perseverance, is as important as mental capacity in the prediction of high achievement. Ericsson and Charness (1994) synthesized the previous literature on the development of expertise. In various sportive and artistic disciplines decades of daily "deliberate practice" was the strongest predictor of world class achievement.

The higher drive, ambition and achievement orientation of creative scientists in comparison to less creative scientists (Feist, 1999; Feist \& Gorman, 1998) can be considered in terms of perseverance. On a hypothetical level, this personality feature is attributed to creative social scientists as well.

$\mathrm{H1}$ : A positive correlation between perseverance and creative potential is expected in social sciences.

\section{Risk taking and creativity}

Risk taking is defined as "the practice of taking action which might have undesirable consequences" (Collins English Dictionary, 2015). Risk takers are attracted by the unknown and always willing to face the challenge of potential failure. They find an intrinsic pleasure in pursuing ideas or actions with somewhat unknown outcomes (Prabhu, 2011). Creativity results from risk taking and uninhibited exploration (Amabile, 1983; Dewett, 2006; Lubart \& Sternberg, 1995) and from the desire to overturn established traditions (Albert \& Runco, 1989). Creativity is described as the exploration of the unknown, the courage to question existing strategies (Besançon, 2011) or the readiness to risk failure (Fidelman, 2008). The uncertainty of the outcome (Sethia, 1989) and the distance from widespread ideas (Lubart et al., 2003) makes creative endeavour in itself a risky attempt.

The likelihood of engaging in risky behaviour depends on the interaction between individual characteristics, environmental conditions and the nature of the task. The individual characteristics refer to (1) risk preferences, (2) risk perceptions and (3) risk propensity. Risk preference is influenced by former outcomes of risky situations. Risk perception is characterized by the focus on either the positive or negative consequences. Risk takers tend to rather concentrate on the positive outcomes of a situation even if they are unlikely 
to happen. Risk propensity is negatively related to the time invested in the decision making process and to available information. However, it is positively related to the cognitive processing of relevant information. The perception of risk taking as a situational state or stable trait is still disputed. The trait theory considers risk taking as a multidimensional construct, related to some other Big Five personality traits. Whereas extraversion and openness are beneficial to risk taking, neuroticism, agreeableness and conscientiousness are detrimental to it. Risk propensity can be considered as a facet of extraversion (Prabhu, 2011).

Amabile (1983) conceived the link between risk taking and creative behaviour through the intrinsic nature of task motivation. Rather than being driven by expected outcomes, the intrinsically motivated person takes pleasure in the task itself (Prabhu, 2011). Intrinsic motivation enhances risk taking, which in turn allows the perception and consideration of apparently irrelevant task aspects. In this way it contributes to a more creative solution. Intrinsic motivation is an acknowledged ingredient for creativity, not only through its relation to risk taking, but also through its relation to autonomy (Amabile, 1983; Prabhu, 2011). Dansky and Silverman (1975) considered playful behaviour as underlying the relation between risk taking and creativity. A playful attitude favours associative fluency. In children, it increases the number of perceived alternate uses for an object. Hence, playfulness boosts risk taking which in turn favours ingenious adaptation to unexpected situations.

The investment approach to creativity considers the creative act as a kind of investment in itself, with potential benefit (internal and external rewards) and potential loss (i.e. time, money, energy, critics) (Lubart \& Sternberg, 1995). Indeed, risk taking has also a latent dark side (Prabhu, 2011). The uncertainty of the outcome follows the general principle of investment. Potential gain is proportional to engaged risk (Lubart \& Sternberg, 1995). In line with the investment approach, risk taking has been associated with innovation in organizations (Dewett, 2006; Fidler \& Johnson, 1984; Jalan \& Kleiner, 1995; Zhou \& George, 2001). Indeed, risk taking is an integral part of the innovation process (Jalan \& Kleiner, 1995). In the organizational framework, resistance against innovation was proportional to perceived risk (Fidler \& Johnson, 1984) and was associated with job dissatisfaction and intended change (Zhou \& George, 2001).

Empirically, Glover and Sautter (1977) investigated the relationship between the four components of divergent thinking and risk taking in graduate students. Whereas high risk takers were characterized by pronounced flexibility and originality, low risk takers were characterized by higher elaboration. Both groups (high and low risk takers) did not distin- 
guish themselves in terms of fluency. Eisenman (1987) found significant relationships between risk taking, creativity and birth order in 200 adult male participants. First born males were found to be more risk taking, which was again related to higher creativity. This relationship between risk taking and creativity did not only affect the first-borns but applied to the total sample. Lubart and Sternberg (1995) assessed risk taking in 44 adults in three different domains: arts, literature and general life. This was realized by means of hypothetic scenarios with an open-ended outcome. The relation between risk taking and creativity was domain specific, with risk taking in a domain related to creativity in the same domain. Dewett (2006) showed willingness to take risks to be a significant predictor of employee creativity. According to the author, it reflects employees' readiness to take risks in the workspace as well as their awareness of the potential drawbacks.

Hypothetically, creative professional practice in social science domains will be related to higher risk taking. This risk predisposition of creative people might be even more pronounced in the social domain than in the general population, because especially in domains focused on human interaction, new ideas can easily backfire.

$\mathrm{H} 2$ : A positive correlation between risk taking and creative potential is expected in the social sciences.

\section{Autonomy and creativity}

Autonomy and independence are key components of the creative personality (Feist, 1999; Oztunc, 2011). They allow creative people to resist group influence (Feist, 1999). Whereas autonomy refers to "the inclination to be free from and independent of other people", independence involves the "state of being free from other people's influence or control" (Oztunc, 2011, p. 224). Creative people feel inherently drawn to both of these tendencies, which favour the production of original and useful ideas (Oztunc, 2011).

Autonomy is one of the personality features most consistently associated with creativity (Feist, 1999). This holds true for theoretical approaches (Amabile, 1983, 1990; Amabile \& Gryskiewicz, 1987; Barron \& Harrington, 1981; Feist, 1999; Mumford \& Gustafson, 1988; Rank, 1932, 1936) but is also found within a long empirical research tradition (Amabile, 1979, 1983; Amabile \& Gryskiewicz, 1987; Barron, 1963, 1965; Helson, 1985; Koestner, Ryan, Bernieri \& Holt, 1984; Kruglanski, Friedman \& Zeevi, 1971; MacKinnon, 1965; Mumford \& Gustafson, 1988; Rogers, 1954; Sheldon, 1995; Wink, 1991).

In terms of social interaction, the autonomy-oriented personality is closely related to other social trait variables: introversion, internal locus of control, intrinsic motivation, self-confidence/arrogance, nonconformity/norm-doubting, desire for solitude and antisocial leanings. Evidence relating creative potential and accomplishment to autonomyoriented personality dispositions is clear (Oztunc, 2011). In the following section a brief 
outline of autonomy-related personality characteristics is offered.

Creative endeavour involves temporary social isolation. At this point, the distinction between autonomy, independence and introversion becomes crucial. Unlike the tendency (autonomy) or the actual state (independence) of liberating oneself from social influence and control, introversion involves maintaining distance from social interaction in various circumstances (Oztunc, 2011). Whereas creative people may be able to deliberately switch between introversion and extraversion (Fidelman, 2008), they still have a stronger inclination towards introversion (Oztunc, 2011).

The internal locus of control of creative people relies on perceiving oneself as responsible for the consequences of one's own behaviour (Oztunc, 2011). The Cognitive Evaluation Theory (Deci \& Ryan, 1985) posits that every environment encompasses two aspects: (1) informational and (2) controlling. The environmental influence on intrinsic motivation is determined through the predominance of one factor over the other.

Constraining environments undermine intrinsic motivation through a depersonalization of thoughts, feelings or actions (Shalley, Zhou \& Oldham, 2004). Intrinsic motivation has been repeatedly associated with creativity (Amabile, 1983). Self-determination theory (Deci \& Ryan, 1985) conceives autonomous behaviour as intrinsically motivated, explaining its link to creativity (Amabile, 1983, 1990). Intrinsic motivation is supposed to boost creativity through its stimulating effect on enjoyment, pleasure, satisfaction, curiosity, cognitive flexibility, risk taking and persistence in the face of failure (Amabile, 1983; Utman, 1997; Zhou \& Shalley, 2003). Only in conjunction with intrinsic motivation can extrinsic motivation be beneficial to creativity (Oztunc, 2011). An information providing environment enables people to draw on their own cognitive resources for establishing a personalized solution to a flexibly defined problem (Shalley et al., 2004).

The link between autonomy/independence and creativity is mediated by selfdirectedness or healthy narcissism (Wink, 1991). The internal orientation of creative people leads to self-confidence and arrogance (Oztunc, 2011). Generally speaking, high scorers on autonomy were found to be characterized by self-assurance, independence and forcefulness (Wink, 1991). Self-directedness predominated over object-directedness in creative people (Wink, 1991). It is simply easier to express your ideas if you do not rely on other people's influence. This is especially true in today's individualistic society, where success largely depends on dominance, self-confidence and arrogance (Oztunc, 2011).

In the empirical literature, the decisions of highly creative people have been shown to be largely unaffected by group judgment (Crutchfield, 1962). Being regarded as social misfits and rebellious in nature, creative people challenge the limits of society. 
This makes them resilient to any kind of group influence (Oztunc, 2011). This kind of nonconformity and norm-doubting of creators is also interpreted as a struggle against societal norms (Helson \& Crutchfield, 1970).

Creative skills, as opposed to interpersonal skills, inherently require a need for solitude. This isolation from external influence might feel uncomfortable to some people. The internal focus of attention and the occasional deliberate avoidance of regular social contact lessen the external influence. This enables autonomous people to differentiate themselves from the group. Intentionally or not, this disposition favours unique and original accomplishments. It is precisely this uniqueness of thoughts and actions that characterize the creative person (Feist, 1999).

In its more extreme form, this need for solitude translates into asocial or even antisocial tendencies (Oztunc, 2011). Constant solitude often results in questioning authority and confrontation with societal norms (Runco, 2006). This deviance can be related to psychoticism (Oztunc, 2011). Indeed, some definitions of psychopathology highlight the notion of deviance. However, being different does not always refer to a pathological state (Runco, 2006).

The higher autonomy, independence and introversion of creative scientists in comparison to less creative scientists (Feist, 1999; Feist \& Gorman, 1998) all belong to the previously mentioned autonomy-related personality characteristics. In the same vein, scientists as compared to non-scientists were found to be more independent, introverted and less sociable (Feist \& Gorman, 1998). Higher autonomy of scientists is postulated for researchers in the social sciences. This assumption refers to the presumed importance of making autonomous decisions in the quotidian working life in social domains, especially in education. Indeed, these professional fields inherently require people to take on a lot of responsibility. This responsibility becomes even larger if social scientists try to implement innovative education or human interaction strategies. This automatically leads to an anticipated higher autonomy in creative social scientists as compared to less creative ones.

H3: A positive correlation between autonomy and creative potential is expected in the social sciences.

\section{Psychoticism and Ego-strength}

An important focus of the between-group perspective lies on the distinctive personality characteristics of artists and scientists. They affect mainly the relative importance of psychopathological tendencies (emotional instability, coldness and rejecting group norms). Whereas higher psychopathological tendencies are expected in the artistic population, 
comparatively higher emotional stability (lower neuroticism vs. higher ego-strength) and higher impulse control (lower psychoticism) are anticipated in the scientific population (Feist, 1998). Even if psychoticism is expected to be lower in scientists as compared to artists (Batey \& Furnham, 2006; Feist, 1998) it still significantly intervenes in scientific creativity (Batey \& Furnham, 2006).

Indeed, creative people combine in an unusual way two apparently opposed personality tendencies. They may well be characterized by psychoticism but they also show considerable ego-strength (Eysenck, 1995; Post, 1994). Ego-strength stimulates the desire to create. This creative aspiration requires additionally exceptional skills, extreme meticulousness and perseverance (Barron, 1969).

Taken together, creative people are in conflict between two divergent inclinations: psychoticism and ego-strength. They compensate their innate lack of inhibition through high emotional stability. Ego-strength acts against impulsive tendencies, which otherwise would result in overwhelming emotions and drives. This ongoing tension guides creative work and reveals an outstanding potential (Eysenck, 1995). Creators are simultaneously more fragile and more resilient than the general population (Barron, 1969). This notion of controlled weirdness (Barron, 1993) or controlled imagination (Carlsson, 2002) finally solves the "paradox" of the creative personality (Eysenck, 1995). It is debatable whether these contradictory tendencies precede creative work (MacKinnon, 1962a, 1962b) or whether they are a side effect of incessant creative activity (Runco, 2006).

The presumed positive association between psychoticism and ego-strength in creative scientists (Batey \& Furnham, 2006) is hypothetically extended to the social sciences. This leads to the following hypotheses:

H4: A positive correlation between psychoticism and creative potential is expected in the social sciences.

H5: A positive correlation between ego-strength and creative potential is expected in social sciences.

\section{Methods}

Participants. The total sample included 156 participants (103 women, 52 men, $M_{\text {Age }}=24.45, S D=3.56$, age range: $19-39$ years). The sample of the general population included 81 participants (37 women, 43 men, $M_{\text {Age }}=25.53, S D=3.81$, age range: $19-39$ years). The sample of social scientists included 75 participants (66 women, 9 men, $M_{\text {Age }}=23.28, S D=2.87$, age range: $19-37$ years). Two professional subgroups, in relation to the social sciences, were included in this sample; they refer to the areas of psychology $\left(n=54,47\right.$ women, 7 men, $\left.M_{\text {Age }}=22.87, S D=2.31\right)$ and education $(n=21$, 
19 women, 2 men, $M_{\text {Age }}=24.33, S D=3.8$ ). The domain of education included social workers, educators and teachers. Social scientists were mainly represented by students of the respective disciplines.

Materials. Creative potential was measured using the Test for Creative ThinkingDrawing Production TCT-DP (Urban \& Jellen, 1995). Taking into account that the creation process transcends disciplines (Sternberg, Grigorenko \& Singer, 2004), the use of one single creativity task across professional subdomains facilitates comparisons. Although the Test for Creative Thinking-Drawing Production (TCT-DP) involves visual rendering it is designed to address, at least to some extent, global imaginary thinking processes. It has been shown to be a reliable predictor of verbal and musical creativity (Scheliga, 1988), creativity in engineering (Jellen \& Bugingo, 1989), high intellectual potential (BenMichael, 1991; Schöpfel, 1992), diversified hobbies, higher and varied artistic and scientific professional aspirations and of teacher creativity ratings (Urban \& Jellen, 1995).

This open-ended drawing test is conceptualized for a wide range of age and ability groups and bases the traditional evaluation on several criteria: continuations; completion; new elements; connections with a line; connections with a theme; boundary breaking, fragment-dependent; boundary breaking, fragment-independent; perspective; humour and affectivity; four kinds of unconventionality and speed (Urban \& Jellen, 1995). An inter -rater reliability of $\alpha=.94$ was established for this first scoring technique. In addition to the sum score, two factor scores were calculated, as suggested by Lubart, Pacteau, Jacquet and Caroff (2010). The originality factor (FO) is based on the following subscores: continuations; completion; boundary breaking-fragment-dependent and boundary breaking-fragment-independent. The adaptation factor (FA) includes: new elements; connections with a line; connections with a theme; perspective; humour and affectivity; and unconventionality.

Statistical Originality SO is a second scoring technique for the TCT-DP. It represents the relative frequency of a given idea with reference to the total sample. This relative frequency refers to each presented fragment. In the end a total score referring to the six fragments is calculated for every participant. This scoring procedure is very similar to the one used to assess originality in divergent thinking tests (Lubart et al., 2010). An originality sum score (Originality) was computed by adding FO and SO.

Finally, the consensual assessment technique CAT (Amabile, 1982) is based on independent scores on a 7-point scale, given in this case by two trained expert judges. These judgments were made without previously providing a definition of the creativity concept (Lubart et al., 2010). The present inter-rater reliability was $\alpha=.86$. 
Perseverance was assessed with the Grit scale (Duckworth, Peterson, Matthews \& Kelly, 2007), representing perseverance and passion for long term goals. By means of exploratory interviews with successful professionals across domains, the authors identified the core characteristics of prominent leaders. Those personalities are characterized by the motivation to take up challenges and preserving curiosity and determination in the long run, despite temporary drawbacks and stagnation. The Grit scale measures two factors, (1) Consistency of Interest and (2) Perseverance of Effort. For the present study only the latter is used. Items are rated on a 5-point Likert scale, ranging from 1, not at all like me, to 5 , very much like me. An internal consistency of $\alpha=.78$ was previously established by Duckworth et al. (2007) for the Perseverance of Effort.

Risk taking was assessed by two different measurement tools. They cover distinctive facets of the construct: (1) Willingness to take Risks and (2) Risk Propensity. Both scales use a 5 point Likert scale (1-strongly disagree, to 5- strongly agree). In previous research, Cronbach's alpha was .90 for Willingness to take Risks and .70 for Risk Propensity (Dewett, 2006). Willingness to take Risks (Dewett, 2006) captures two aspects: (a) the readiness to engage consciously in risky behaviour in the workplace and (b) the awareness of potential negative consequences. The conscious awareness of possible drawbacks is relevant to calculated risk. The scale of Risk Propensity was adapted by Dewett (2006) from Sitkin and Weingart (1995). It measures the cross-situational trait level of risk taking and refers to an individual's risk taking tendencies.

Autonomy was measured by a five-item scale. Originally developed by Ibarra and Andrews (1993) it was adapted by Dewett (2006). It covers the situational aspects of autonomy supportiveness in the work environment. More specifically, it assesses the degree of perceived management control (Ibarra \& Andrews, 1993). The questionnaire uses a fivepoint Likert scale, ranging from 1, strongly disagree, to 5, strongly agree. An alpha coefficient of .86 was previously established by Dewett (2006).

The Minnesota Multiphasic Personality Inventory (MMPI-2; Hathaway \& McKinley, 1996) was implemented for measuring psychoticism and ego-strength; through the subscales Psychopathic deviate (Pd) and Ego-strength (Es). The Pd-scale measures psychopathological tendencies, in the form of neurotic and psychotic disorders. People who score high on this scale have often been in trouble with the law, without being mentally, culturally or intellectually disadvantaged (Hathaway \& McKinley, 2000). The MMPI is an acknowledged measure of psychopathology (Eysenck, 1995). The Ego-strength (Es-scale) is an indicator of general mental health and successful life management; it appraises a person's capacities to deal with critical life experiences and to overcome challenging situations. More spe- 
cifically, it measures adaptability, resilience and mental resources. In everyday life, those characteristics translate into spontaneity, contact with reality, a feeling of personal accomplishment and physical health (Hathaway \& McKinley, 2000).

Procedure. Data were collected by undergraduate psychology students in 2012 at the University of Luxembourg, within the framework of a course on differential psychology. The testing was conducted individually or in small groups. The procedure took about one and a half hours. The creativity test (TCT-DP) was administered first, followed by the questionnaires (willingness to take risks, autonomy, risk propensity, perseverance of effort, psychopathic deviate and ego-strength). Participants were offered the possibility of obtaining feedback on their results as well as a small amount of remuneration.

Results. In the Results section the descriptive statistics, correlations, multiple regressions and mean comparison tests of the measured variables are presented. In order to test the established hypotheses, correlations were calculated for the general population, for the total sample of social scientists, and separately for the sub groups of psychologists and educators. For methodological reasons, due to limited sample sizes, multiple regressions were only calculated for the general population of non-scientists $(n=81)$ and for the sample of social scientists $(n=75)$. Whereas the mentioned personality variables function as independent (predictor) variables, the various scores of the TCT-DP act as criterion variables.

\section{Table 1}

Means and standard deviations for the general population (non-scientists, $\mathrm{N}=\mathbf{8 1}$ )

\begin{tabular}{|c|c|c|}
\hline Variables & & $S D$ \\
\hline TCT-DP ${ }^{a}$ & 22.38 & 9.74 \\
\hline Originality factor $\mathrm{FO}^{b}$ & 10.47 & 6.94 \\
\hline Statistical Originality $\mathrm{SO}^{\mathrm{c}}$ & 3.42 & 2.43 \\
\hline Originality $^{d}$ & 13.89 & 7.76 \\
\hline Adaptation factor $\mathrm{FA}^{e}$ & 11.91 & 4.68 \\
\hline Consensual Assessment Technique CAT ${ }^{f}$ & 3.55 & 1.48 \\
\hline perseverance of effort ${ }^{g}$ & 22.33 & 4.40 \\
\hline willingness to take risks ${ }^{h}$ & 26.41 & 5.16 \\
\hline risk propensity ${ }^{i}$ & 12.36 & 3.52 \\
\hline autonomy $^{j}$ & 17.40 & 3.63 \\
\hline psychoticism $^{k}$ & 19.90 & 3.85 \\
\hline ego-strength ${ }^{\prime}$ & 30.25 & 4.68 \\
\hline
\end{tabular}

Note. ${ }^{a}$ Theoretical range $=+2$ to $+45 ;{ }^{b}$ Theoretical range $=0$ to $+27 ;{ }^{~}$ Theoretical range $=0$ to $+10 ;{ }^{d}$ Theoretical range $=+1$ to +32 ; ${ }^{\text {T}}$ Theoretical range $=0$ to +18 ; ${ }^{\top}$ Theoretical range $=+1$ to +7 ; ${ }^{9}$ theoretical range $=+7$ to

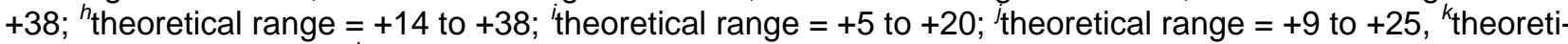
cal range $=+12$ to +29 , theoretical range $=+21$ to +38 . 
Table 2

Means and standard deviations for psychologists $(\mathrm{N}=54)$

\begin{tabular}{lll}
\hline \multicolumn{1}{c}{ Variables } & \multicolumn{1}{c}{$\boldsymbol{M}$} & \multicolumn{1}{c}{$\boldsymbol{S D}$} \\
\hline TCT-DP $^{a}$ & 22.56 & 10.55 \\
Originality factor FO $^{b}$ & 11.74 & 8.22 \\
Statistical Originality SO $^{c}$ & 3.04 & 2.31 \\
Originality $^{d}$ & 14.78 & 9.13 \\
${\text { Adaptation factor } \mathrm{FA}^{e}}^{\text {Consensual Assessment Technique CAT }^{f}}$ & 10.81 & 4.25 \\
perseverance of effort $^{g}$ & 3.69 & 1.40 \\
willingness to take risks $^{h}$ & 21.94 & 3.64 \\
risk propensity $^{i}$ & 26.80 & 3.34 \\
autonomy $^{j}$ & 12.00 & 3.56 \\
psychoticism $^{k}$ & 18.69 & 2.55 \\
ego-strength $^{\prime}$ & 20.21 & 4.36 \\
& 30.57 & 4.41 \\
\hline
\end{tabular}

Note. ${ }^{a}$ Theoretical range $=+3$ to $+52 ;{ }^{b}$ Theoretical range $=0$ to +34 ; ${ }^{C}$ Theoretical range $=0$ to +10 ; ${ }^{d}$ Theoreti-

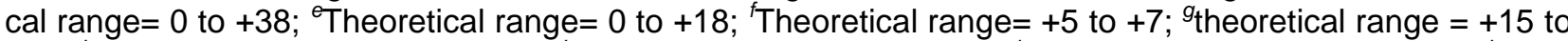
+29 ; ${ }^{\prime}$ theoretical range $=+16$ to +35 ; 'theoretical range $=+5$ to +22 ; ' theoretical range $=+14$ to +25 , "ktheoretical range $=+12$ to +29 , 'theoretical range $=+19$ to +39 .

Table 3

Means and standard deviations for educators $(\mathrm{N}=\mathbf{2 1})$

\begin{tabular}{|c|c|c|}
\hline Variables & $\pi$ & $S D$ \\
\hline TCT-DP & 24.33 & 8.89 \\
\hline Originality factor $\mathrm{FO}^{b}$ & 11.95 & 7.56 \\
\hline Statistical Originality $\mathrm{SO}^{c}$ & 3.14 & 2.17 \\
\hline Originality $^{d}$ & 15.10 & 8.50 \\
\hline Adaptation factor $F A^{e}$ & 12.38 & 3.99 \\
\hline Consensual Assessment Technique CAT ${ }^{f}$ & 3.83 & 1.38 \\
\hline perseverance of effort ${ }^{g}$ & 21.86 & 3.62 \\
\hline willingness to take risks ${ }^{h}$ & 25.86 & 4.81 \\
\hline risk propensity ${ }^{i}$ & 12.24 & 2.47 \\
\hline autonomy ${ }^{j}$ & 18.33 & 3.79 \\
\hline psychoticism $^{k}$ & 19.02 & 3.58 \\
\hline ego-strength' & 28.57 & 3.79 \\
\hline
\end{tabular}

Note. ${ }^{a}$ Theoretical range $=+8$ to $+44 ;{ }^{b}$ Theoretical range $=0$ to +26 ; ${ }^{\circ}$ Theoretical range $=0$ to $+8{ }^{d}$ Theoretical range $=+1$ to +29 ; $^{\mathrm{e}}$ Theoretical range $=+7$ to +18 ; ${ }^{\text {T }}$ Theoretical range $=+1.50$ to +6.50 ; ${ }^{9}$ theoretical range $=$ +15 to +29 ; ${ }^{h}$ theoretical range $=+17$ to +34 ; 'theoretical range $=+7$ to +16 ; ' theoretical range $=+12$ to +25 ,

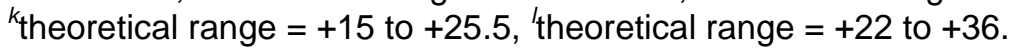


Table 4

Means and standard deviations for social scientists $(\mathbf{N}=75)$

\begin{tabular}{lll}
\hline \multicolumn{1}{c}{ Variables } & \multicolumn{1}{c}{$\boldsymbol{M}$} & \multicolumn{1}{c}{$\boldsymbol{S D}$} \\
\hline TCT-DP $^{a}$ & 23.05 & 10.09 \\
${\text { Originality factor } \mathrm{FO}^{b}}$ & 11.80 & 7.99 \\
Statistical Originality SO $^{c}$ & 3.07 & 2.26 \\
Originality $^{d}$ & 14.87 & 8.90 \\
Adaptation factor FA $^{e}$ & 11.25 & 4.21 \\
Consensual Assessment Technique CAT $^{f}$ & 3.73 & 1.38 \\
perseverance of effort $^{g}$ & 21.92 & 3.61 \\
willingness to take risks $^{h}$ & 26.53 & 4.46 \\
risk propensity $^{i}$ & 12.07 & 3.28 \\
autonomy $^{j}$ & 18.59 & 2.92 \\
psychoticism $^{k}$ & 19.87 & 4.17 \\
ego-strength $^{\prime}$ & 30.01 & 4.32 \\
\hline
\end{tabular}

Note. ${ }^{a}$ Theoretical range $=+3$ to $+52 ;{ }^{b}$ Theoretical range $=0$ to +34 ; ${ }^{C}$ Theoretical range $=0$ to +10 ; ${ }^{d}$ Theoreti-

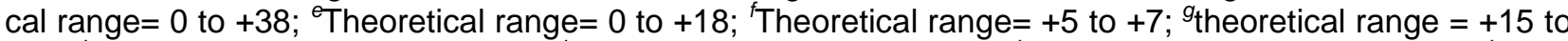
+29 ; ${ }^{\prime}$ theoretical range $=+16$ to +35 ; 'theoretical range $=+5$ to +22 ; ' theoretical range $=+12$ to +25 , "ktheoretical range $=+12$ to +29 , 'theoretical range $=+19$ to +39 .

Table 5

Correlation Matrix of Personality and Creativity Variables for the General Population (Non-scientists, $\mathbf{N}=81$ )

\begin{tabular}{|c|c|c|c|c|c|c|c|c|c|c|c|c|}
\hline Variables & 1 & 2 & 3 & 4 & 5 & 6 & 7 & 8 & 9 & 10 & 11 & 12 \\
\hline 1. TCT-DP & 1 & $.90^{* \star}$ & $.25^{*}$ & $.88^{* \star}$ & $.75^{\star \star}$ & $.80^{* \star}$ & -.12 & -.09 & $-.20^{*}$ & -.03 & -.13 & .07 \\
\hline 2. $\mathrm{FO}$ & & 1 & .18 & $.95^{\star \star}$ & $.38^{* *}$ & $.82^{* *}$ & -.04 & -.09 & -.17 & .02 & -.13 & $.21^{*}$ \\
\hline 3. SO & & & 1 & $.47^{* *}$ & $.25^{*}$ & $.21^{*}$ & -.03 & .09 & .01 & -.05 & -.11 & -.02 \\
\hline 4. Originality & & & & 1 & $.42^{* *}$ & $.80^{* *}$ & -.05 & -.05 & -.15 & .00 & -.15 & .18 \\
\hline 5. FA & & & & & 1 & $.46^{* *}$ & $-.19^{*}$ & -.06 & -.17 & -.08 & -.08 & -.15 \\
\hline 6. CAT & & & & & & 1 & -.18 & -.16 & $-.30^{\star *}$ & -.10 & -.10 & .01 \\
\hline 7. perseverance of effort & & & & & & & 1 & -.06 & .04 & .06 & 13 & -.07 \\
\hline 8. willingness to take risks & & & & & & & & 1 & $.45^{\star *}$ & $.31^{* *}$ & .01 & 13 \\
\hline 9. risk propensity & & & & & & & & & 1 & -.06 & .08 & 17 \\
\hline 10. autonomy & & & & & & & & & & 1 & -.13 & $.36^{* *}$ \\
\hline 11. psychoticism & & & & & & & & & & & 1 & $-.32^{* *}$ \\
\hline 12. ego-strength & & & & & & & & & & & & 1 \\
\hline
\end{tabular}

Note. ${ }^{*} p<.05$ level; ${ }^{* *} p<.01$ level. 
Table 6

Correlation Matrix of Personality and Creativity Variables for Psychologists $(\mathbf{N}=54)$

\begin{tabular}{|c|c|c|c|c|c|c|c|c|c|c|c|c|}
\hline Variables & 1 & 2 & 3 & 4 & 5 & 6 & 7 & 8 & 9 & 10 & 11 & 12 \\
\hline 1. TCT-DP & 1 & $.92^{* *}$ & $.36^{* *}$ & $.93^{* *}$ & $.69^{* *}$ & $.74^{\star *}$ & $.25^{*}$ & $.29^{*}$ & .03 & $.57^{\star \star}$ & .07 & .03 \\
\hline 2. $\mathrm{FO}$ & & 1 & $.27^{*}$ & $.97^{* *}$ & $.37^{* \star}$ & $.72^{\star *}$ & $.30^{*}$ & $.19^{*}$ & .04 & $.46^{\star *}$ & .10 & .06 \\
\hline 3. $\mathrm{SO}$ & & & 1 & $.50^{* *}$ & $.38^{* *}$ & $.27^{*}$ & -.01 & $.27^{*}$ & .01 & $.25^{*}$ & .08 & $-.25^{*}$ \\
\hline 4. Originality & & & & 1 & $.43^{* *}$ & $.71^{* *}$ & $.26^{*}$ & $.24^{*}$ & .04 & $.48^{\star *}$ & .11 & -.01 \\
\hline 5. FA & & & & & 1 & $.45^{\star \star}$ & .06 & $.36^{* *}$ & .00 & $.49^{* *}$ & .05 & -.03 \\
\hline 6. CAT & & & & & & 1 & .18 & .14 & .01 & $.38^{* *}$ & -.08 & $.28^{*}$ \\
\hline 7. perseverance of effort & & & & & & & 1 & .22 & .19 & -.02 & .20 & -.03 \\
\hline 8. willingness to take risks & & & & & & & & 1 & $.51^{\star *}$ & .09 & -.23 & $-.30^{*}$ \\
\hline 9. risk propensity & & & & & & & & & 1 & -.16 & -.12 & -.03 \\
\hline 10. autonomy & & & & & & & & & & 1 & .14 & -.06 \\
\hline 11. psychoticism & & & & & & & & & & & 1 & $-.32^{*}$ \\
\hline 12. ego-strength & & & & & & & & & & & & 1 \\
\hline
\end{tabular}

Note. ${ }^{*} p<.05$ level; ${ }^{* *} p<.01$ level.

Table 7

Correlation Matrix of Personality and Creativity Variables for Educators $(N=21)$

\begin{tabular}{|c|c|c|c|c|c|c|c|c|c|c|c|c|}
\hline Variables & 1 & 2 & 3 & 4 & 5 & 6 & 7 & 8 & 9 & 10 & 11 & 12 \\
\hline 1. TCT-DP & 1 & $.90^{*}$ & .33 & $.88^{*}$ & $.53^{\star}$ & $\begin{array}{c}.75^{*} \\
*\end{array}$ & .16 & -.09 & $.39^{*}$ & .17 & -.06 & $.47^{*}$ \\
\hline 2. $\mathrm{FO}$ & & 1 & .31 & $.97^{*}$ & .10 & $.87^{*}$ & .06 & -.11 & .32 & .06 & -.12 & $.50^{\star}$ \\
\hline 3. $\mathrm{SO}$ & & & 1 & $.54^{*}$ & 14 & .35 & .14 & -.18 & -.07 & .33 & $-.51^{* *}$ & $.53^{* *}$ \\
\hline 4. Originality & & & & 1 & .12 & $.86^{*}$ & .09 & -.14 & .26 & .14 & -.24 & $.58^{* *}$ \\
\hline 5. FA & & & & & 1 & .02 & .28 & -.01 & .31 & .12 & .09 & .17 \\
\hline 6. CAT & & & & & & 1 & -.01 & -.17 & .24 & -.08 & -.12 & $.46^{*}$ \\
\hline 7. perseverance of effort & & & & & & & 1 & .25 & .30 & $-.39 *$ & -.14 & .24 \\
\hline 8. willingness to take risks & & & & & & & & 1 & $.69^{* *}$ & .05 & -.14 & .09 \\
\hline 9. risk propensity & & & & & & & & & 1 & .00 & -.04 & .19 \\
\hline 10. autonomy & & & & & & & & & & 1 & -.14 & .17 \\
\hline 11. psychoticism & & & & & & & & & & & 1 & $-.51^{\star *}$ \\
\hline 12. ego-strength & & & & & & & & & & & & 1 \\
\hline
\end{tabular}

Note. ${ }^{*} p<.05$ level; ${ }^{* *} p<.01$ level. 
Table 8

Correlation Matrix of Personality and Creativity Variables for Social Scientists (Psychologists and Educators) $(\mathbf{N}=75)$

\begin{tabular}{|c|c|c|c|c|c|c|c|c|c|c|c|c|}
\hline Variables & 1 & 2 & 3 & 4 & 5 & 6 & 7 & 8 & 9 & 10 & 11 & 12 \\
\hline 1. TCT-DP & 1 & $.92^{* \star}$ & $.36^{* *}$ & $.92^{* *}$ & $.65^{\star \star}$ & $.74^{\star \star}$ & $.23^{*}$ & .18 & .10 & $.39^{* *}$ & .05 & .12 \\
\hline 2. FO & & 1 & $.28^{*}$ & $.97^{* *}$ & $.30^{* *}$ & $.76^{* *}$ & $.24^{*}$ & 10 & .09 & $.31^{* *}$ & .05 & .16 \\
\hline 3. SO & & & 1 & $.51^{* *}$ & $.32^{\star *}$ & $.29^{*}$ & .03 & .14 & -.01 & $.27^{*}$ & -.06 & -.07 \\
\hline 4. Originality & & & & 1 & $.35^{\star *}$ & $.75^{* *}$ & 22 & .13 & .08 & $.35^{\star *}$ & .03 & .12 \\
\hline 5. $\mathrm{FA}$ & & & & & 1 & $.34^{* *}$ & .11 & $.23^{*}$ & .06 & $.34^{* *}$ & .03 & -.02 \\
\hline 6. CAT & & & & & & 1 & .13 & .04 & .06 & .21 & -.10 & $.30^{* *}$ \\
\hline 7. perseverance of effort & & & & & & & 1 & .23 & .21 & -.15 & 12 & .04 \\
\hline 8. willingness to take risks & & & & & & & & 1 & $.54^{* *}$ & .08 & -.19 & -.17 \\
\hline 9. risk propensity & & & & & & & & & 1 & -.11 & -.11 & .00 \\
\hline 10. autonomy & & & & & & & & & & 1 & .06 & .03 \\
\hline 11. psychoticism & & & & & & & & & & & 1 & $-.32^{* \star}$ \\
\hline 12. ego-strength & & & & & & & & & & & & 1 \\
\hline
\end{tabular}

Note. ${ }^{*} p<.05$ level; ${ }^{* *} p<.01$ level.

Table 9

Predictors of TCT-DP Consensual Assessment Technique in the General Population

\begin{tabular}{lcc}
\hline \multicolumn{3}{c}{ Creative Potential } \\
\multicolumn{1}{c}{ Predictor } & $\Delta \boldsymbol{R}^{2}$ & $\boldsymbol{\beta}$ \\
\hline Model 1 & .08 \\
\multicolumn{2}{l}{ Risk Propensity } \\
$n$
\end{tabular}

Note. ${ }^{*} p<.05$ level; ${ }^{* *} p<.01$ level.

Table 10

Predictors of TCT-DP Sum Score in Social Scientists

\begin{tabular}{lcc}
\hline \multicolumn{2}{c}{ Creative Potential } \\
\multicolumn{1}{c}{ Predictor } & $\Delta \boldsymbol{R}^{2}$ & $\boldsymbol{\beta}$ \\
\hline Model 1 & .14 & \\
$\quad$ Autonomy & & $.39^{* *}$ \\
Model 2 & .08 & \\
$\quad$ Autonomy & & $.43^{* *}$ \\
$\quad$ Perseverance & & $.30^{\star *}$ \\
$n$ & 74 & \\
\hline
\end{tabular}

Note. ${ }^{*} p<.05$ level; ${ }^{* *} p<.01$ level. 
Table 11

Predictors of TCT-DP Factor Originality FO in Social Scientists

\begin{tabular}{lcc}
\hline \multicolumn{2}{c}{ Creative Potential } \\
\multicolumn{1}{c}{ Predictor } & $\Delta \boldsymbol{R}^{2}$ & $\boldsymbol{\beta}$ \\
\hline Model 1 & .09 & \\
$\quad$ Autonomy & & $.31^{\star *}$ \\
Model 2 & .07 & \\
$\quad$ Autonomy & & $.36^{\star *}$ \\
$\quad$ Perseverance & & $.29^{\star *}$ \\
$n$ & 74 & \\
\hline
\end{tabular}

Note. ${ }^{*} p<.05$ level; ${ }^{* *} p<.01$ level.

Table 12

Predictors of TCT-DP Statistical Originality SO in Social Scientists

\begin{tabular}{lcc}
\hline \multicolumn{2}{c}{ Creative Potential } \\
\multicolumn{1}{c}{ Predictor } & $\Delta \boldsymbol{R}^{2}$ & $\boldsymbol{\beta}$ \\
\hline Model 1 \\
Autonomy \\
$n$
\end{tabular}

Note. ${ }^{*} p<.05$ level; ${ }^{* *} p<.01$ level.

Table 13

Predictors of TCT-DP Originality Sum Score (FO + SO) in Social Scientists

\begin{tabular}{lcc}
\hline \multicolumn{1}{c}{ Creative Potential } \\
\multicolumn{1}{c}{ Predictor } & $\Delta \boldsymbol{R}^{2}$ & $\boldsymbol{\beta}$ \\
\hline Model 1 & .11 & \\
$\quad$ Autonomy & & $.35^{\star *}$ \\
Model 2 & .06 & \\
$\quad$ Autonomy & & $.39^{\star *}$ \\
$\quad$ Perseverance & & $.28^{\star *}$ \\
$n$ & 74 & \\
\hline
\end{tabular}

Note. ${ }^{*} p<.05$ level; ${ }^{* *} p<.01$ level. 
Table 14

Predictors of TCT-DP Factor Adaptation FA in Social Scientists

\begin{tabular}{lcc}
\hline \multicolumn{3}{c}{ Creative Potential } \\
\multicolumn{1}{c}{ Predictor } & $\Delta \boldsymbol{R}^{2}$ & $\boldsymbol{\beta}$ \\
\hline Model 1 & .10 \\
Autonomy & & $.34^{\star *}$ \\
$n$ & 74 & \\
\hline
\end{tabular}

Note. ${ }^{*} p<.05$ level; ${ }^{* *} p<.01$ level.

Table 15

Predictors of TCT-DP Consensual Assessment Technique in Social Scientists

\begin{tabular}{|c|c|c|}
\hline \multicolumn{3}{|c|}{ Creative Potential } \\
\hline Predictor & $\Delta R^{2}$ & $\beta$ \\
\hline Model 1 & .08 & \\
\hline Ego-strength & & $.30^{* *}$ \\
\hline$n$ & 176 & \\
\hline
\end{tabular}

Note. ${ }^{*} p<.05$ level; ${ }^{* *} p<.01$ level.

The correlations within the separate samples (general population and social scientists) were tested for bilateral significant differences, using Fisher's z prime formula. There was a significant difference for the correlation between perseverance and TCT-DP sum score $(z=-2.17, p \leq .05)$ and TCT-DP CAT $(z=-2.26, p \leq .05)$. There was a significant difference for the correlation between autonomy and TCT-DP sum score $(z=-2.70, p \leq .01)$, TCT-DP SO ( $z=-2.00, p \leq .05)$, TCT-DP Originality $(z=-2.24, p \leq .05)$ and TCT-DP FA $(z=-2.66, p \leq .01)$. One can conclude that autonomy and perseverance were significantly more related to creativity in the social sciences than in the general population. 
Table 16

Creativity and Personality Means for Social Scientists and the General Population

\begin{tabular}{|c|c|c|c|c|}
\hline & \multicolumn{2}{|c|}{ Groups } & \multirow[b]{2}{*}{$t$} & \multirow[b]{2}{*}{$d f$} \\
\hline & $S C$ & $G P$ & & \\
\hline TCT-DP & $\begin{array}{l}23.05 \\
(10.09)\end{array}$ & $\begin{array}{l}22.38 \\
(9.74)\end{array}$ & .42 & 154 \\
\hline Originality factor $\mathrm{FO}$ & $\begin{array}{l}11.80 \\
(7.99)\end{array}$ & $\begin{array}{l}10.47 \\
(6.94)\end{array}$ & 1.11 & 154 \\
\hline Statistical Originality SO & $\begin{array}{l}3.07 \\
(2.26)\end{array}$ & $\begin{array}{l}3.42 \\
(2.43)\end{array}$ & -.94 & 154 \\
\hline Originality & $\begin{array}{l}14.87 \\
(8.90)\end{array}$ & $\begin{array}{l}13.89 \\
(7.76)\end{array}$ & .73 & 154 \\
\hline Adaptation factor FA & $\begin{array}{l}11.25 \\
(4.21)\end{array}$ & $\begin{array}{l}11.91 \\
(4.68)\end{array}$ & -.93 & 154 \\
\hline Consensual Assessment Technique CAT & $\begin{array}{l}3.73 \\
(1.38)\end{array}$ & $\begin{array}{l}3.55 \\
(1.48)\end{array}$ & .80 & 154 \\
\hline perseverance of effort & $\begin{array}{l}21.92 \\
(3.61)\end{array}$ & $\begin{array}{l}22.33 \\
(4.40)\end{array}$ & -.64 & 154 \\
\hline willingness to take risks & $\begin{array}{l}26.53 \\
(4.46)\end{array}$ & $\begin{array}{l}26.41 \\
(5.16)\end{array}$ & .16 & 154 \\
\hline risk propensity & $\begin{array}{l}12.07 \\
(3.28)\end{array}$ & $\begin{array}{l}12.36 \\
(3.52)\end{array}$ & -.54 & 154 \\
\hline autonomy & $\begin{array}{l}18.59 \\
(2.92)\end{array}$ & $\begin{array}{l}17.40 \\
(3.63)\end{array}$ & $2.27^{*}$ & 154 \\
\hline psychoticism & $\begin{array}{l}19.87 \\
(4.17)\end{array}$ & $\begin{array}{l}19.90 \\
(3.85)\end{array}$ & -.04 & 154 \\
\hline ego-strength & $\begin{array}{l}30.01 \\
(4.32)\end{array}$ & $\begin{array}{l}30.25 \\
(4.68)\end{array}$ & -.32 & 154 \\
\hline
\end{tabular}

Note. ${ }^{*}=p<.05,{ }^{* *}=p<.01$.Standard Deviations appear in parentheses below means.

Next, t-tests were conducted to compare social scientists and the general population on the measured creativity and personality variables. Both groups distinguished themselves significantly on autonomy, with social scientists having higher autonomy than the general population $(t=2.27, p \leq .05)$.

In the following section, each hypothesis will be examined separately.

1. A positive correlation between perseverance and creative potential is expected in the social sciences.

This hypothesis was supported in social scientists (TCT-DP: $r=.23, p \leq .05$; $\beta=.30, p \leq .01$; FO: $r=.24, p \leq .05 ; \beta=.29, p \leq .01$; Originality: $\beta=.28, p \leq .01$ ) and in the subgroup of psychologists, (TCT-DP: $r=.25, p \leq .05$; FO: $r=.30, p \leq .05$; Originality: $r=.25, p \leq .05)$. However, this relationship solely applied to originality facets of creative production (FO, Originality) and not to the adaptation factor (FA). 
Whereas perseverance turned out to be a positive predictor, especially of creative originality in social scientists (see Table 11 and Table 13), it was not a significant predictor of creativity in the general population (see Table 9). Furthermore, the correlation comparisons gave support to the notion that perseverance was significantly more correlated with creativity in the social sciences than in the general population. However, there was no significant mean difference between both groups regarding perseverance (see Table 16).

2. A positive correlation between risk taking and creative potential is expected in the social sciences.

This hypothesis was confirmed; especially in the subgroup of psychologists but also to a lesser extent in educators. For creative psychologists willingness to take risks was correlated with creativity scores (TCT-DP: $r=.29, p \leq .05$; FO: $r=.19, p \leq .05$; SO: $r=.27, p \leq .05$; FA: $r=.24, p \leq .05$ : CAT: $r=.36, p \leq .01$ ), for educators, creativity and risk propensity were correlated in particular (TCT-DP: $r=.39, p \leq .05$ ).

However, risk taking in either form turned out not to be a positive predictor of creativity in social scientists in the multiple regression analyses (see Table 10 to Table 15). On the other hand, risk propensity was the only significant predictor of creativity in the general population (CAT: $r=-.30, p \leq .05 ; \beta=-.30, p \leq .01$ ). It was a highly significant negative predictor. Hence, risk taking seems to be differently related to creativity in social scientists than in the general population. However, the difference in correlations did not reach statistical significance, according to Fisher's z prime formula. Furthermore, there was also no significant mean difference in risk taking between both groups (see Table 16).

3. A positive correlation between autonomy and creative potential is expected in the social sciences.

This hypothesis was largely confirmed in social scientists and especially in the subgroup of psychologists: social scientists (TCT-DP: $r=.39, p \leq .01, \beta=.43, p \leq .01$; FO: $r=.31, p \leq .01 ; \beta=.36, p \leq .01$; SO: $r=.27, p \leq .05, \beta=.27, p \leq .05$; Originality: $r=.35, p \leq .01, \beta=.39, p \leq .01 ; \mathrm{FA}: r=.34, p \leq .01, \beta=.34, p \leq .01)$ and psychologists (TCT-DP: $r=.57, p \leq .01$; FO: $r=.46, p \leq .01$; SO: $r=.25, p \leq .05$; Originality: $r=.48, p \leq .01$; FA: $r=.49, p \leq .01$; CAT: $r=.38, p \leq .01)$.

In the general population, autonomy was not a significant predictor of creative potential (see Table 9). Furthermore, comparing social scientists and the general population, there was a significant difference for the correlation between autonomy and creative potential. It can be concluded that autonomy intervened at a significantly greater 
level in the creative potential of social scientists than in the creative potential of the general population. Finally, t-tests revealed that both groups distinguished themselves significantly on autonomy, with social scientists having higher autonomy than the general population $(t=2.27, p \leq .05)$.

4. A positive correlation between psychoticism and creative potential is expected in the social sciences.

This hypothesis was contradicted. In the subgroup of educators psychoticism was even highly negatively related to creativity in the form of $\mathrm{SO}(r=-.51, p \leq .01)$. Furthermore, psychoticism did not turn out to be a significant predictor of creative potential, either in social scientists or in the general population (see Table 9 to Table 15). Equally, there was no significant difference between both groups on psychoticism (see Table 16) and in the correlation between psychoticism and creative potential.

5. A positive correlation between ego-strength and creative potential is expected in the social sciences.

This hypothesis was supported in social scientists and especially in the subgroup of educators: social scientists (CAT: $r=.30, p \leq .01 ; \beta=.30, p \leq .01$ ) and educators (TCT-DP: $r=.47, p \leq .05$; FO: $r=.50, p \leq .05$; SO: $r=.53, p \leq .01$; Originality: $r=.58, p \leq .01)$. In educators, ego-strength was particularly related to originality. However, in the subgroup of psychologists this hypothesis was contradicted. There was a significant negative correlation between ego-strength and $\mathrm{SO}(r=-.25, p \leq .05)$.

In the general population, ego-strength was not a significant predictor of creative potential (see Table 9). Ego-strength seems to make a more important contribution to the creative potential of social scientists than to that of the general population. However, according Fisher's z prime indicator, this differential intervention did not reach a significant level. There was also no significant mean difference in ego-strength between the groups of social scientists and the general population (see Table 16).

\section{Discussion}

Creative social scientists were particularly autonomous, perseverant and emotionally stable (see Table 10 to Table 15). Autonomy and perseverance were significantly more important for creativity in social scientists than for creativity in the general population. Creative psychologists were especially autonomous, perseverant, risk taking and emotionally unstable (see Table 6) and creative educators were especially emotionally stable, impulse controlled and risk taking (see Table 7). Whereas autonomy was especially important for creativity in psychologists, ego-strength (emotional stability) was particularly important for creativity in educators. Regardless of professional discipline, the observed 
characteristics in social scientists are all undeniably valuable features. Apart from exhibiting creative skills, creative social scientists additionally displayed several beneficial domain-general job-related characteristics (autonomy, perseverance and emotional stability).

While willingness to take risks was more important for creativity in psychologists, risk propensity was more important for creativity in educators (see Table 6 and Table 7). Willingness to take risks refers essentially to the professional context and risk propensity apprehends risk taking on a more general trait level. Indeed, some similarities can undoubtedly be drawn between both professions. They both deal with human interaction and empathy. It seems that essentially in these humanistic professions a reasonably "provocative" behaviour is related to creative practice. Apparently, certain barriers have to be overcome in order to establish creative human interactions. It appears that humanitarian professions select those individuals among creative people, who are willing to engage in risky behaviour. Interestingly, risk propensity was even a negative predictor for creativity in the general population (see Table 9) and it was also the only personality trait that predicted creativity in the general population. The general assumption of a positive association between risk taking and creativity in social scientists was confirmed. It can however not be concluded that risk taking is significantly more important for creativity in social scientists than in the general population.

According to the correlations and multiple regressions (see Table 6 to Table 15), one can conclude that personality intervenes more strongly in social scientists and the respective sub-disciplines than in creativity in the general population. The creative personality indeed showed some specificity according to the professional domain and the respective subdomains. These results argue in favour of the differential approach to creativity, in which personality features are thought to vary in terms of the considered domain (Lubart \& Sternberg, 1995). Apparently, the creative personality is not as domain general as was initially proposed and it obviously makes sense to distinguish between different professions and professional subdomains in the analysis of the creative personality profile. This point should be considered in future research, by differentiating between creativity within the broader categories of arts, science and everyday life, and within the subdomains of activity in these sectors.

The fact that certain features are particularly important within the respective disciplines is surely not a coincidence. This might arise from the professionalization process, which selects people who display these supplementary features. On the other hand, it may also be that the selection of a specific discipline encourages creative people to gradually develop or express the respective characteristics. The latter option could be explained by the significance of the appropriate environment. 
Autonomy was the most important personality predictor for creativity in social scientists (see Table 10 to Table 15), especially in the subgroup of psychologists (see Table 6). This confirms the findings of Feist (1999) and Feist and Gorman (1998), according to which the more creative scientists were more autonomous and independent than the less creative ones. Furthermore, autonomy turned out to be significantly more important for creativity in social scientists than for creativity in the general population (nonscientists) and both groups distinguished themselves significantly in autonomy (see Table 16). In the general population autonomy did not play any role with regard to creativity (see Table 5). This is again in line with the findings of Feist and Gorman (1998), according to which scientists were more independent than non-scientists. Accordingly, the special importance of autonomy for creativity in scientists can be generalized to social scientists. The distinctive importance of autonomy relied on its relationship to originality. Autonomy favours originality by allowing people to distinguish themselves from others. Autonomy related independence encourages people to transgress the boarders of the already known. Indeed, independence of judgment is important if one has to go against the crowd in quest of novelty (Runco, 2006; Sternberg \& Lubart, 1995).

Whether this autonomy is person-related or context-related is not absolutely clear, because the perception of one's management style as autonomous or not is also a function of the personality of the observer (Sheldon, 1995). Hence, the person-context interaction determines the level of exploitation of opportunistic contextual factors for employee creativity (Shalley et al., 2004). The underlying hypothesis refers to the enhanced resistance against controlling external forces. This releases the creative potential of self-determined people (Amabile, 1983; Hennessey et al., 1989; Hennessey \& Zbikowski, 1993; Sheldon, 1995; Schubert, 1988). It is commonly known as natural immunity against or freedom from extrinsic constraints (Amabile, 1983; Hennessey \& Zbikowski, 1993). Because the perceived autonomy supportiveness of the environment is linked to autonomy as a personality feature, one could easily imagine that fostering an autonomous workstyle in young children influences, in turn, the respective personality characteristic. Indeed, psychological immunization against environmental constraints can be acquired through specific training and experiences and through appropriate home and classroom environments (Hennessey et al., 1989).

This would provide an explanation for the positive relationship between perceived environmental autonomy supportiveness and trait creativity. In the present study one could imagine that the continuous encouragement of an autonomous working style throughout school or job career influenced in return the respective personality trait. This again colours the environmental perception of granted autonomy supportiveness. It contributes fi- 
nally to a further enhancement of creative potential; this can be considered as a positive feedback loop. Taken together, our findings open new directions for research in the pedagogical context, concerning the importance of fostering an autonomous working style, already in young children. The same principle can be applied to students and employees. However, education for autonomy has to be distinguished from absolute permissiveness. Parents and teachers should still provide the necessary boundaries, in which children have the freedom to choose an appropriate reaction (Runco, 2006).

Self-determination theory highlights the interaction between personality and environment in the interpretation of environmental characteristics as autonomy supportive or not. Beside this subjective environmental interpretation, the objective degree of control also exerts an influence on autonomy and subsequent creativity. In this case, autonomy refers to the conferred degree of liberty, independence, freedom of choice and personal control in the execution of a task (Hackman \& Oldham, 1980; Hennessey \& Amabile, 2010). In any case, it is highly plausible that creative psychologists (or social scientists) actively choose to work in an autonomy-supportive environment that allows them to take larger responsibilities.

In future research, an additional autonomy measurement tool could be used. Indeed, the evaluation of autonomy as a general trait is more transposable to the classroom context than a measure of an autonomous working environment. This would then enhance the generalizability of the present results to the school context. Hence, the assessment of autonomy as perceived management style as well as a personality trait would allow the relationship between both facets of this construct and their relative importance for creativity to be clarified.

Besides autonomy, perseverance was also an important predictor of creativity in social scientists (see Table 19 to Table 15), especially in the subgroup of psychologists (see Table 6). This confirms the findings of Feist (1999) and Feist and Gorman (1998), where creative scientists were more achievement oriented, ambitious and driven than their less creative peers. Furthermore, perseverance was significantly more important for creativity in social scientists than for creativity in the general population (non-scientists). This is also in line with the findings of Feist and Gorman (1998), which found scientists to be more driven, ambitious and achievement oriented than non-scientists. Accordingly, the stated importance of perseverance for creativity in scientists can be extended to creativity in social scientists. Similarly to the case of autonomy, the importance of perseverance relied on its relationship to originality. It seems that perseverance essentially intervenes in the innovative aspect of a creation. A strong determination with regard to work seems neces- 
sary to overcome existing frameworks and create pioneering ideas. Indeed, perseverance is thought to intervene especially in divergent thinking; in the early stages of the creation process (Besançon, 2011). Abandoning the creative process early in its initial stages may result in more mainstream creations, where the innovation lies within the existing frameworks and not beyond.

Depending on the respective scoring techniques of the TCT-DP, ego-strength played an additional role besides autonomy and perseverance for creativity in social scientists (see Table 15). However, ego-strength was not significantly more important for creativity in social scientists than for creativity in the general population (non-scientists). Also there were no significant differences in ego-strength between both groups (see Table 16). This finding is not in line with that of Feist and Gorman (1998), who found scientists to be more emotionally stable and impulse controlled than non-scientists. The importance of ego-strength for creativity in scientists can accordingly be generalized to creativity in social scientists. However, it seems that ego-strength only plays a minor role as regards creativity in social scientists.

Whereas ego-strength was positively related to creativity in educators (see Table 7), it was negatively related to creativity in psychologists (see Table 6). The positive correlation indicates that original pedagogues showed high ego-strength. Even though the TCTDP does not directly assess creative teaching practices, it can be hypothesized that the creative trait transposes to the teaching or education context, at least if environmental conditions are favourable to creative expression. In educators the role of ego-strength for creativity was even complemented by negative psychoticism (see Table 7). The opposite extreme of the psychoticism spectrum is commonly conceptualized as impulse control (Eysenck, 1993, 1995). Impulse control again relates to higher conscientiousness (Costa \& McCrae, 1992). Original educators seem to be very emotionally stable, impulse controlled and conscientious, which are undeniably valuable features in the educative context. Especially in educators, creativity seems to rely on mental strength and balance. It follows that ego-strength and impulse control (low psychoticism) are essential for creative education practices. Indeed emotional stability and impulse control are highly important in a field in which professionals get constantly challenged. The common understanding of a good teacher or educator is somebody who controls his/her emotional reactions and who does not let himself/herself become overwhelmed by emotional outbursts. This emotional control is even more important when trying to implement creative teaching or education techniques. Indeed, such practices could easily backfire. In this case a strong resilience capacity is favourable. The lack of emotional coping strategies could 
lead creative pedagogues to become overwhelmed by the consequences of their own creative practice.

In the present populations both features (psychoticism and ego-strength) were not found to converge, as suggested by Eysenck (1995). Therefore, the importance of psychoticism for creativity in scientists cannot be generalized to creativity in social scientists. It is an interesting observation that in social scientists creativity was essentially fostered by mental strength and not by conflicted personality types. This contradicts the general assumption made by the so called "creativity-madness" link (Lombroso, 1891; Ellis, 1926; Lange-Eichbaum, 1930). This specific personality constellation may be reserved for eminent creators (Eysenck, 1995) or for particular domains of creative achievement, which according to some authors (e.g. Batey \& Furnham, 2006) might especially be the arts. It does apparently not extend to the social sciences and the general population.

A drawback of the present study clearly lies in the failure to use domain-specific creativity measurement tools, because only the TCT-DP was used. In future research this shortcoming could be addressed by introducing additional domain specific measurement tools for creativity. This would foster the development of domain specific creativity models for artistic professions, scientific professions and everyday life.

\section{REFERENCES}

Albert, R. S. \& Runco, M. A. (1989). Independence and cognitive ability in gifted and exceptionally gifted boys. Journal of Youth and Adolescence, 18, 221-230.

Amabile, T. (1979). Effects of external evaluation on artistic creativity. Journal of Personality and Social Psychology, 37, 221-233.

Amabile, T. (1982). Social psychology of creativity: A consensual assessment technique. Journal of Personality and Social Psychology, 43, 997-1013; DOI:10.1037/00223514.43.5.997.

Amabile, T. (1983). The social psychology of creativity: A componential conceptualization. Journal of Personality and Social Psychology, 45, 357-376.

Amabile, T. (1990). Within you, without you. In M. A. Runco \& R. S. Albert (Eds.), Theories of creativity (pp. 61-91). Newbury Park, CA: Sage.

Amabile, T. \& Gryskiewicz, S. S. (1987). Creativity in the R\&D laboratory. (Technical report number 30). Greensboro, NC: Center for Creative Leadership.

Baer, J. (1998). The case for domain specificity. Creativity Research Journal, 11, 173-177.

Barron, F. (1965). The psychology of creativity. In F. Barron, W. Dement, W. Edwards \& J. M. Olds (Eds.), New Directions in Psychology II (pp. 1-134). New York: Holt, Rinehart \& Winston. 
Barron, F. (1963). Creativity and psychological health. Princeton, NJ: Van Nostrand.

Barron, F. (1969). Creative person and creative process. New York: Holt, Rinehart \& Winston.

Barron, F. (1988). Putting creativity to work. In R. J. Sternberg (Ed.), The nature of creativity (pp. 76-98). New York: Cambridge University Press.

Barron, F. (1993). Controllable oddness as a resource in creativity. Psychological Inquiry, 4, $182-184$.

Barron, F. \& Harrington, D. M. (1981). Creativity, intelligence, and personality. Annual Review of Psychology, 32, 439-476.

Batey, M. \& Furnham, A. (2006). Creativity, intelligence, and personality: A critical review of the scattered literature. Genetic, Social, and General Psychology Monographs, 132(4), 355-429.

Ben-Michael, M. (1991, July-August). Identification of gifted (achieving and underachieving) Turkish and Morrocan elementary school students. Paper presented at the meeting of the 9th World Conference on Gifted and Talented Children, The Hague, NL.

Besançon, M. (2011). Les clés de la créativité [The keys of creativity]. Cerveau \& Psycho, 46, 48-53.

Carlsson, I. (2002). Anxiety and flexibility of defence related to high or low creativity. Creativity Research Journal, 14, 341-349.

Costa, P. T. \& McCrae, R. R. (1992). NEO-PI-R: Revised NEO personality inventory and NEO-FFI: NEO five-factor inventory [Professional manual]. Odessa, FL: Psychological Assessment Resources.

Cox, C. M. (1926). Genetic studies of genius. The early mental traits of three hundred geniuses (Vol. 2). Stanford: Stanford University Press.

Cropley, A. J. (1997). Fostering creativity in the classroom: General principles. In M. A. Runco (Ed.), The creativity research handbook (Vol.1, pp. 83-114). Cresskill NJ: Hampton Press.

Crutchfield, R. S. (1962). Conformity and creative thinking. In H. Gruber, G. Terell \& M. Wertheimer (Eds.), Contemporary approaches to creative thinking (pp. 120-140). New York: Atherton.

Csikszentmihalyi, M. (1988). Motivation and creativity: Toward a synthesis of structural and energetic approaches to cognition. New ldeas in Psychology, 2, 159-176.

Dansky, J. \& Silverman, I. (1975). Play: A general facilitator of associative fluency. Developmental Psychology, 11, 104.

Deci, E. L. \& Ryan, R. M. (1985). Intrinsic motivation and self-determination in human behaviour. New York: Plenum. 
Dewett, T. (2006). Exploring the role of risk in employee creativity. Journal of Creative Behaviour, 40(1), 27-45.

Duckworth, A., Peterson, C., Matthews, M. \& Kelly D. (2007). Personality processes and individual differences. Grit: Perseverance and passion for long-term goals. Journal of Personality and Social Psychology, 92,1087-1101.

Eisenman, R. (1987). Creativity, birth order, and risk-taking. Bulletin of the Psychodynamic Society, 25, 87-88.

Ellis, H. (1926). A study of British genius. New York: Houghton-Mifflin.

Ericsson, K. A. \& Charness, N. (1994). Expert performance: Its structure and acquisition. American Psychologist, 49, 725-747.

Eysenck, H. J. (1993). Creativity and personality: Suggestions for a theory. Psychological Inquiry, 4, 147-178.

Eysenck, H. J. (1995). Genius: The natural history of creativity. Cambridge: Cambridge University Press.

Feist, G. J. (1998). A meta-analysis of personality in scientific and artistic creativity. Personality and Social Psychology Review, 2, 290-309.

Feist, G. J. (1999). Affect in artistic and scientific creativity. In S. W. Russ (Ed.), Affect, creative experience and psychological adjustment (pp. 9-108). Philadelphia: Taylor \& Francis.

Feist, G. J. \& Gorman, M. E. (1998). The psychology of science: Review and integration of a nascent discipline. Review of General Psychology, 2, 3-47.

Fidelman, M. (2008). The different paths to creativity. Electronic Journal of Research in Educational Psychology, 6, 1-28.

Fidler, L. A. \& Johnson, J. D. (1984). Communication and innovation implementation. Academy of Management Review, 9, 704-711.

Gardner, H. (1993). Creating minds. New York: Basic Books.

Glover, J. A. \& Sautter, F. (1977). Relation of four components of creativity to risk-taking preferences. Psychological Reports, 41, 88-94.

Gruber, H. E. (1983). History and creative work: From the most ordinary to the most exalted. Journal of the History of the Behavioural Sciences, 19, 4-14.

Hackman, J. R. \& Oldham, G. R. (1980). Work redesign. Reading, MA: Addison-Wesley. Harper Collins. (2015). Collins English dictionary. Retrieved from http://www.collinsdictionary.com/dictionary/english/risk-taking?showCookiePolicy=true Hathaway, S. R. \& McKinley, J. C. (2000). MMPI-2: Minnesota multiphasic personality inventory-2 [Questionnaire and manual]. (R. Engel (Ed.) Trans.). Bern: Hans Huber. 
Hathaway, S. R. \& McKinley, J. C. (1996). MMPI-2: Inventaire multiphasique de personnalité du Minnesota-2 [Questionnaire et manuel]. [Minnesota multiphasicpersonality inventory-2 (Questionnaire and manual)]. Paris: Editions du Centre de Psychologie Appliquée.

Helson, R. (1985). Which of those young women with creative potential became productive? Personality in college and characteristics of parents. In R. Hogan \& W. H. Jones (Eds.), Perspectives in personality (Vol. 1, pp. 49-80). Greenwich, CT: JAI Press.

Helson, R. \& Crutchfield, R. S. (1970). Mathematicians: The creative researcher and the average PhD. Journal of Consulting and Clinical Psychology, 34, 250-257.

Hennesey, B. A. \& Amabile, T. M. (2010). Creativity. Annual Review of Psychology, 61, 569-598.

Hennessey, B. A. \& Zbikowski, S. (1993). Immunizing children against the negative effects of reward: A further examination of intrinsic motivation training techniques. Creativity Research Journal, 6, 297-307.

Hennessey, B. A., Amabile, T. \& Martinage, M. (1989). Immunizing children against the negative effects of reward. Contemporary Educational Psychology, 14, 212-227.

Howe, M. J. A. (1989). Fragments of genius: The strange face of idiots savants. London: Routledge.

Ibarra, H. \& Andrews, S. B. (1993). Power, social influence, and sense making: Effects of network centrality and proximity on employee perceptions. Administrative Science Quarterly, 38, 277-303.

Jalan, A. \& Kleiner, B. H. (1995). New developments in developing creativity. Journal of Managerial Psychology, 10, 20-30.

Jellen, H. G. \& Bugingo, E. (1989). Assessing creative problem solving potential in engineering students: The application of the Test for Creative Thinking - Drawing Production to pentathlon participants. Journal of Studies in Technical Careers, 11, 223-235.

Kirsch, C., Houssemand, C. \& Lubart, T. (2014, March). Creativity in Different Professions: The Role of an Autonomous Working Style. Paper presented at the meeting of the Inter-Disciplinary Net, Prague, Czech Republic.

Koestner, R., Ryan, R., Bernieri, F. \& Holt, K. (1984). Setting limits on children's behaviour: The differential effects of controlling vs. informational styles on intrinsic motivation and creativity. Journal of Personality, 52, 233-248.

Kruglanski, A., Friedman, E. \& Zeevi, G. (1971). The effects of intrinsic incentives on some qualitative aspects of task performance. Journal of Personality, 39, 606-617.

Lange-Eichbaum, W. (1930). The problem of genius. New York: Macmillan.

Lombroso, C. (1891). The man of genius. London: Walter Scott. 
Lubart, T. (2003). In search of creative intelligence. In R.J. Sternberg \& J. Lautrey (Eds.), Models of intelligence: International perspectives (pp. 279-292). Washington, DC: American Psychological Association.

Lubart. T. \& Sternberg, R. J. (1995). An investment approach to creativity: Theory and data. In S. M. Smith, T. B. Ward \& R. A. Finke (Eds.), The creative cognition approach (pp. 271-302). Cambridge MA: MIT Press.

Lubart, T., Mouchiroud, C., Tordjman, S. \& Zenasni, F. (2003). Psychologie de la créativité [Psychology of creativity]. Paris: Armand Colin.

Lubart, T., Pacteau, C., Jacquet, A-Y. \& Caroff, X. (2010). Children's creative potential: An empirical study of measurement issues. Learning and Individual Differences, 20, 388-392; DOI: doi.org/10.1016/j.lindif.2010.02.006.

Mackinnon, D. W. (1962a). The nature and nurture of creative talent. American Psychologist, 17, 484-495.

MacKinnon, D. W. (1962b).The personality correlates of creativity: A study of American architects. In G. S. Nielsen (Ed.), Proceedings of the XIV International Congress of Applied Psychology, Copenhagen 1961. (Vol. 2, pp.11-39). Copenhagen: Munksgaard.

MacKinnon, D. W. (1965). Personality and the realization of creative potential. American Psychologist, 20, 273-281.

McCrae, R. R. (1987). Creativity, divergent thinking, and openness to experience. Journal of Personality and Social Psychology, 52, 1258-1265.

Mumford, M. D. \& Gustafson, S. B. (1988). Creativity syndrome: Integration, application, and innovation. Psychological Bulletin, 103, 27-43.

Osborn, A. (1963). Applied imagination: Principles and procedures of creative thinking. New York: Scribner's.

Oztunc, G. (2011). Personality: Autonomy and independence. In M. A. Runco \& S. R. Pritzker (Eds.), Encyclopedia of creativity (Vol.2, pp. 224-227). San Diego, CA: Academic Press.

Post, F. (1994). Creativity and psychopathology: A study of 291 world famous men. British Journal of Psychiatry, 165, 22-34.

Prabhu, V. (2011). Risk-taking. In M. A. Runco \& S. R. Pritzker (Eds.), Encyclopedia of Creativity (Vol.2, pp. 319-322). San Diego, CA: Academic Press.

Rank, O. (1932). Art and artist: Creative urge and personality development. (C. F. Atkinson, Trans.). New York: Knopf.

Rank, O. (1936). Truth and reality: A life history of human will. (J. Taft, Trans.). New York: Knopf. 
Roe, A. (1953). The making of a scientist. New York: Dodd Mead.

Rogers, C. R. (1954). Toward a theory of creativity. ETC, A Review of General Semantics, 11, 249-260.

Rossman, J. (1931). The psychology of the inventor. Washington DC: Inventors Publishing Company.

Runco, M. A. (2006). Reasoning and personal creativity. In J. C. Kaufman \& J. Baer (Eds.), Creativity and reason in cognitive development (pp. 99-116). Cambridge MA: Cambridge University Press.

Scheliga, J. (1988). Musikmachen und die Förderung der Kreativität. (Unveröfflichte Diplomarbeit) Psycholgisches Institut II, Universität Hamburg. [Music making and the stimulation of creativity (Unpublished master's thesis) Psychological Institute II, University of Hamburg].

Schöpfel, J. (1992). Kreatives Schreiben. Identifikation und Förderung sprachlich-kreativ begabter Jugendlicher [Creative writing. Identification and fostering of linguisticcreatively gifted young people]. Europäische Hochschulschriften, Band 390, Reihe 6.

Schubert, S. P. (1988). Creativity and the ability to cope. In F. Flach (Ed.), The creative mind (pp. 97-114). Buffalo, NY: Bearly.

Sethia, N. K. (1989). The shaping of creativity in organizations. Academy of Management Journal, 1, 224-228.

Shalley, C.E., Zhou, J. \& Oldham, G. R. (2004). Effects of personal and contextual characteristics on creativity: Where should we go from here? Journal of Management, 30, 933-958.

Sheldon, K. (1995). Creativity and self-determination in personality. Creativity Research Journal, 8, 25-36.

Sitkin, S. B. \& Weingart, L. R. (1995). Determinants of risky decision-making behaviour: A test of the mediating role of risk perceptions and propensity. Academy of Management Journal, 38, 1573-1592.

Sternberg, R. J. \& Lubart, T. (1995). Defying the crowd: Cultivating creativity in a culture of conformity. New York: Free Press.

Sternberg, R. J., Grigorenko, E. L. \& Singer, J. L. (Eds.). (2004). Creativity: From potential to realization. Washington, DC: American Psychological Association.

Urban, K. K. \& Jellen, H. G. (1995). TSD-Z: Test zum Schöpferischen Denken - Zeichenerisch [Manual]. [TCT-DP Test for Creative Thinking- Drawing Production (Manual)]. Frankfurt: Swets Test Services. 
Utman, C. H. (1997). Performance effects of motivational states. A meta-analysis. Personality and Social Psychology Review, 1, 170-182.

Wink, P. (1991). Self- and object-directness in adult women. Journal of Personality, 59, 769-791.

Zhou, J. \& George, J. M. (2001). When job dissatisfaction leads to creativity: Encouraging the expression of voice. Academy of Management Journal, 44, 682-696.

Zhou, J. \& Shalley, C. E. (2003). Research on employee creativity: A critical review and direction for future research. Research in Personnel and Human Resource Management, 22, 165-217.

Corresponding author at: Christiane Kirsch, University of Luxemburg, ECCS Research Unit, Route de Diekirch, L-7201, Walferdange, Luxembourg

E-mail: christijeanne.kirsch@gmail.com

Corresponding author at: Todd Lubart, Laboratoire Adaptations Travail Individu (EA4469), Université Paris Descartes, Paris Cité Sorbonne, 71 Avenue Edouard Vaillant, 92100 Boulogne-Billancourt, France

E-mail: todd.lubart@parisdescartes.fr

Corresponding author at: Claude Houssemand, University of Luxembourg, Faculté des Lettres, des Sciences Humaines, des Arts et des Sciences de l'Education, Maison des Sciences Humaines, 11, Porte des Sciences, L-4366 Esch-sur-Alzette E-mail: claude.houssemand@uni.lu 